\title{
Surface Modification of NaCl Particles with Metal Films Using the Polygonal Barrel-Sputtering Method
}

\author{
Satoshi Akamaru, Mitsuhiro Inoue, Takayuki Abe*
}

Hydrogen Isotope Research Center, University of Toyama, Toyama, Japan.

Email: *tabe@ctg.u-toyama.ac.jp

Received May $22^{\text {nd }}, 2013$; revised June $21^{\text {st }}, 2013$; accepted July $3^{\text {rd }}, 2013$

Copyright (C) 2013 Satoshi Akamaru et al. This is an open access article distributed under the Creative Commons Attribution License, which permits unrestricted use, distribution, and reproduction in any medium, provided the original work is properly cited.

\begin{abstract}
In this study, the surfaces of $\mathrm{NaCl}$ particles were modified with metal films using the polygonal barrel-sputtering method. When $\mathrm{Pt}$ was sputtered on $\mathrm{NaCl}$ particles, the individual particles changed from white to metallic. Characterization of the treated samples indicated that thin Pt metal films were uniformly deposited on the $\mathrm{NaCl}$ particles. Immersion of the treated $\mathrm{NaCl}$ particles in water revealed that they floated to the surface of the water with the increase in the immersion time, although their original cubic shapes remained unchanged. The floating phenomenon of the Pt-coated $\mathrm{NaCl}$ particles, as mentioned above, suggests that $\mathrm{NaCl}$ was dissolved by the permeation of water through invisible defects such as grain boundaries in the Pt films, leading to the formation of hollow particle-like materials. It should be noted that uniform film deposition on the $\mathrm{NaCl}$ particles could also be achieved by sputtering with $\mathrm{Au}$ or $\mathrm{Cu}$. Based on the obtained results, our sputtering method allows uniform surface modification of water-soluble and water-reactive powders that cannot be treated by conventional wet process using water.
\end{abstract}

Keywords: Particle Surface Modification; Ionic Crystal; Dry Process; Sputtering Technique; $\mathrm{NaCl}$

\section{Introduction}

Modification of particle surfaces is an important technique in various fields of science and industry. For example, particle surface modification plays an important role in the preparation of catalysts [1-3], photocatalysts [4,5], and electrocatalysts [6-9]. Surface modification is also frequently used to add functions such as gas-sensing to powders [10].

Among the available methods for particle surface modification, wet processes including electroplating [11, 12] and impregnation [1-3,7] are used the most widely to prepare functionalized powders. However, wet processes result in wastewater streams which not only require treatment to remove any harmful residual chemicals, but may also be potentially damaging to the environment. In addition, powders such as ionic crystals and organic semiconductors that are soluble or reactive in water cannot be treated by conventional wet processes containing surface modification processes using water. Thus, only a limited number of powders can be modified using wet processes.

In contrast, sputtering [13-16], which is categorized as

"Corresponding author. a dry process, modifies material surfaces without water. As a result, no wastewater is discharged during surface modification using the sputtering technique. Moreover, sputtering allows even surface modification of water-soluble and water-reactive materials. These advantages of sputtering address the problems of wet processes, mentioned above. However, conventional sputtering systems can only treat planar materials.

Based on this background, we developed a novel surface modification method for powders using the sputtering technique, which we call the "polygonal barrel-sputtering method" [17-32]. The polygonal barrel-sputtering method has been successfully used for uniform surface modification of particles composed of metals [17], alloys [18], metal oxides [19-24], polymers [25-27], and carbon [28-32]. In this study, the surfaces of $\mathrm{NaCl}$ particles were modified with metal films using the polygonal barrel-sputtering method to demonstrate the application of our method to the surface modification of water-soluble and water-reactive powders.

\section{Experimental}

\subsection{Preparation of Samples}

A schematic diagram of the polygonal barrel-sputtering 
method used to prepare the samples is shown in Figure 1. In this sputtering system, a polygonal barrel containing a powder is rotated or oscillated during sputtering. The powder is stirred by this action, allowing uniform modification of the particles. In this study, particle surface modification was performed using a Pt (purity: 99.95\%), $\mathrm{Au}(99.99 \%)$, or Cu plate $(99.99 \%)$ with a size of W 50 $\mathrm{mm} \times \mathrm{L} 100 \mathrm{~mm}$ as a target for sputtering. The AC power for sputtering was supplied by RF power generation (13.56 MHz). Samples were prepared following reported procedures [17-32]. NaCl powder (particle size: $250-500 \mu \mathrm{m}$, Kanto Chemical or The Salt Industry Center of Japan) was introduced into a hexagonal barrel and then the barrel was placed in a vacuum chamber. Subsequently, the vacuum chamber was carefully evacuated using rotary and diffusion pumps. After the pressure was decreased to less than $8 \times 10^{-4} \mathrm{~Pa}$, Ar gas (purity: $99.9999 \%$ ) was slowly introduced into the chamber. Sputtering was then performed at a gas pressure of Ar of $2 \mathrm{~Pa}$ without heating while the hexagonal barrel was rotated at $3.5 \mathrm{rpm}$ to stir the $\mathrm{NaCl}$ particles. The $\mathrm{AC}$ power and sputtering time were $100 \mathrm{~W}$ and $30 \mathrm{~min}$ for sputtering of both Pt and $\mathrm{Au}$. Cu was sputtered at $195 \mathrm{~W}$ for $5 \mathrm{~h}$. After sputtering, $\mathrm{N}_{2}$ gas was gradually introduced into the vacuum chamber until it reached atmospheric pressure, at which point the prepared samples could be extracted.

\subsection{Characterization of Samples}

The appearance of the $\mathrm{NaCl}$ powder sample before and after sputtering was observed using an optical microscope (LV150; Nikon). The modified $\mathrm{NaCl}$ particles were characterized using a field emission scanning electron microscope (FE-SEM; JSM-6701F; JEOL) with an energy-dispersive X-ray spectroscope (EDS; JED-2300; JEOL) and X-ray diffraction (XRD; PW1825/00; Philips).

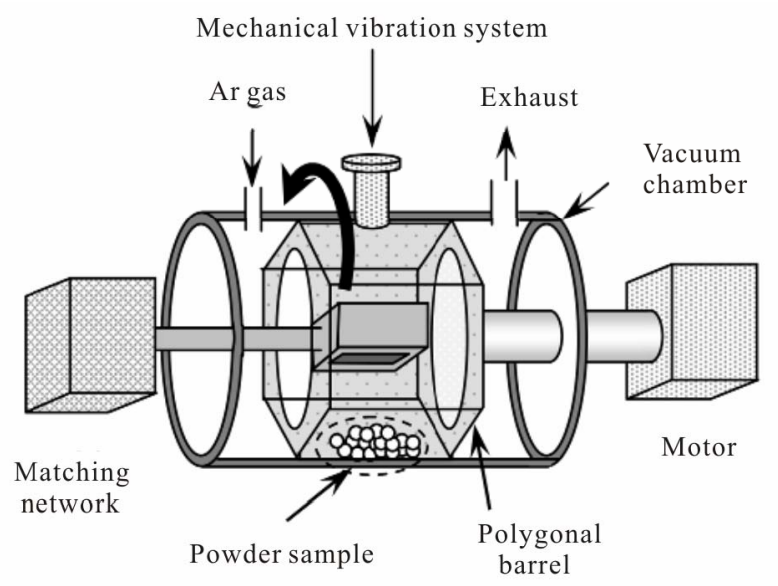

Figure 1. Schematic diagram of the polygonal barrel-sputtering system.
For an immersion test, the treated sample was added to pure water. The solution used for the immersion test was analyzed by X-ray fluorescence analysis (XRF; PW2300, Philips) using a Rh X-ray tube.

\section{Results and Discussion}

Figures 2(1a) and (1b) show photographs of $\mathrm{NaCl}$ powder before and after sputtering with $\mathrm{Pt}$, respectively. Before sputtering, the $\mathrm{NaCl}$ sample was white and the shape of each particle was obscure. After sputtering, the $\mathrm{NaCl}$ sample changed from white to metallic and the cubic shape of the particles was clearly seen because of their apparent contrast. Optical microscopic images of the untreated and treated $\mathrm{NaCl}$ particles are presented in Figure 2(2). The untreated $\mathrm{NaCl}$ particles were transparent and their surfaces were relatively rough (Figure 2(2a)). Following treatment, all of the particles were a uniform metallic color and their clear shading visibly emphasized the roughness of the original surfaces of the $\mathrm{NaCl}$ particles (Figure 2(2b)). Overall, the $\mathrm{NaCl}$ particles were uniformly covered with metallic films by the polygonal barrel-sputtering method.

The $\mathrm{NaCl}$ particles before and after sputtering with $\mathrm{Pt}$ were observed by FE-SEM and EDS. The results obtained at low magnification $(\times 110)$ are presented in Figure 3 (a: before, $b$ : after sputtering). The FE-SEM images reveal that the treated and untreated particles possessed similar morphology (Figure 3(1)). In the EDS mapping images, however, Pt element was detected only for the sputtered particles, as shown in Figure 3(2). Remarkably, the shape of Pt mapping is similar to those of $\mathrm{Na}$ and $\mathrm{Cl}$ mappings, suggesting that the Pt films were uniformly deposited on the $\mathrm{NaCl}$ particles. It is emphasized that a relatively smooth surface was observed in an FE-SEM image obtained at a high magnification of $\times 190,000$ (Figure 4), implying that the deposited Pt films contained no remarkable pores or damage.

The deposited Pt films were also characterized by XRD. Figures 5(a) and (b) show XRD patterns of $\mathrm{NaCl}$ samples before and after sputtering with Pt, respectively,

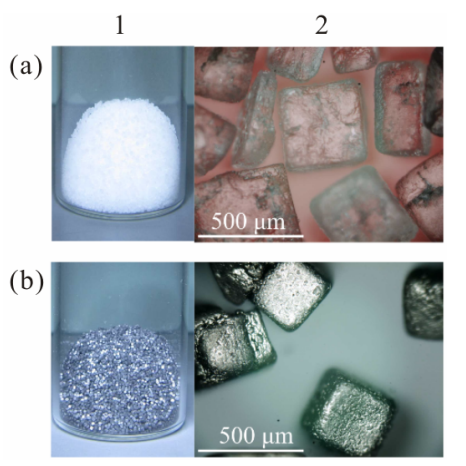

Figure 2. (1) Photographs and (2) optical microscope images of $\mathrm{NaCl}$ samples (a) before and (b) after sputtering with Pt. 


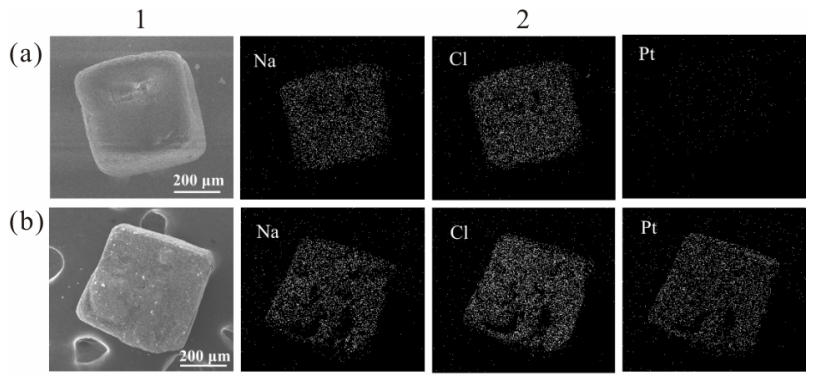

Figure 3. (1) FE-SEM images and (2) EDS mapping images of $\mathrm{NaCl}$ particles in the samples (a) before and (b) after sputtering with Pt (magnification: × 110).

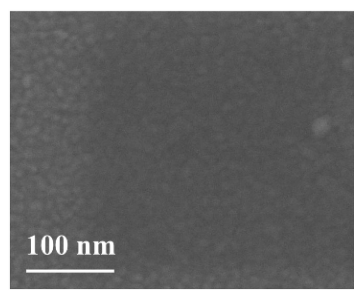

Figure 4. FE-SEM image of the surface of a NaCl particle after sputtering with Pt (magnification: $\times 190,000)$.

obtained in the $2 \theta$ range of $30^{\circ}-50^{\circ}$. Before sputtering, two peaks were observed at $2 \theta=32.06^{\circ}$ and $45.44^{\circ}$, which were assigned to the $\mathrm{NaCl}(200)$ and $\mathrm{NaCl}(220)$ peaks, respectively, that are characteristic of $\mathrm{NaCl}$ with a cubic structure (JCPDS No. 05-0628). The XRD pattern of the Pt-sputtered sample contained two additional peaks at $2 \theta=39.99^{\circ}$ and $46.39^{\circ}$ along with the diffraction peaks of $\mathrm{NaCl}$. The new peaks in this pattern correspond to the signals of $\operatorname{Pt}(111)$ and $\operatorname{Pt}(200)$, demonstrating that the deposited films consisted of Pt metal with a face-centered cubic structure (JCPDS No. 04-0802). However, the observed Pt peaks were slightly broad. In our previous study on the surface modification of $\mathrm{Al}_{2} \mathrm{O}_{3}$ particles with Pt films, broadness of the Pt peaks was attributed to the thinness of the layer of deposited Pt [19]. On this basis, the appearance of broad Pt peaks in Figure 5(b) most likely shows that the Pt films deposited on the $\mathrm{NaCl}$ particles were very thin.

The physical properties of the $\mathrm{NaCl}$ sample coated with a film of Pt metal were further examined by an immersion test. Photographs of the sample in a bottle containing pure water during the immersion test are shown in Figures 6(A)-(D). After an immersion time of $0.5 \mathrm{~min}$, the samples had sunk to the bottom of the bottle (Figure 6(A)), clearly indicating that the $\mathrm{NaCl}$ particles were completely covered with the Pt films. However, some samples floated up the surface of the solution after $1 \mathrm{~min}$ (Figure 6(B)). The number of the floating particles gradually increased as the immersion time extended (Figure 6(C)). After $2 \mathrm{~min}$, all of the particles floated at the surface (Figure 6(D)). It should be noted that the

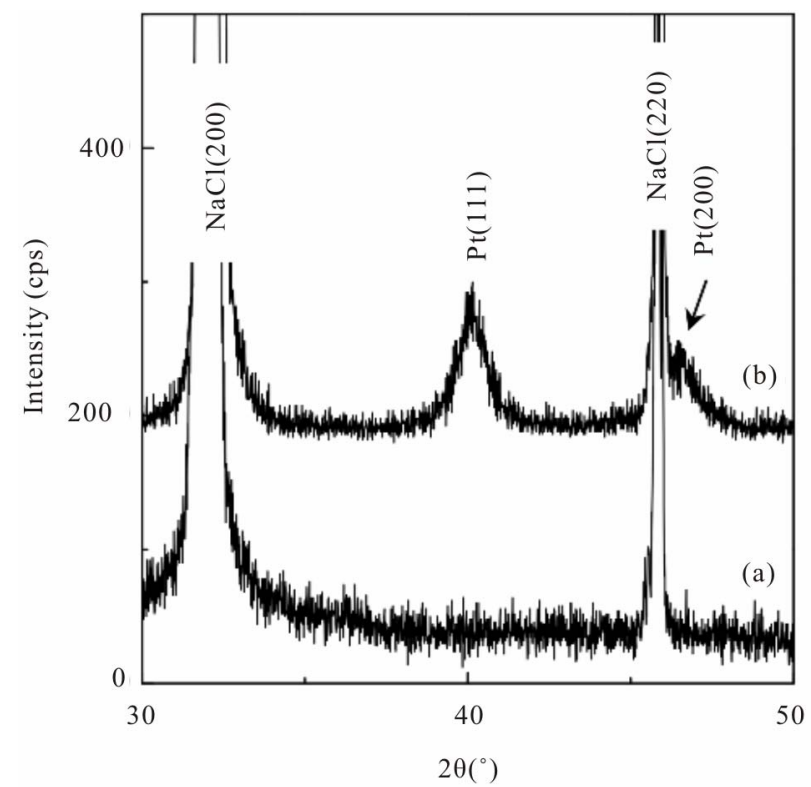

Figure 5. XRD patterns of $\mathrm{NaCl}$ samples (a) before and (b) after sputtering with $\mathbf{P t}$.
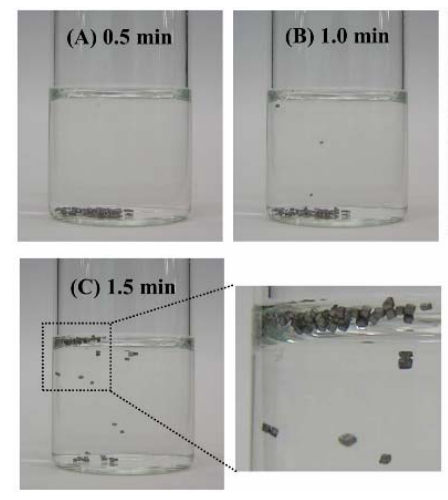
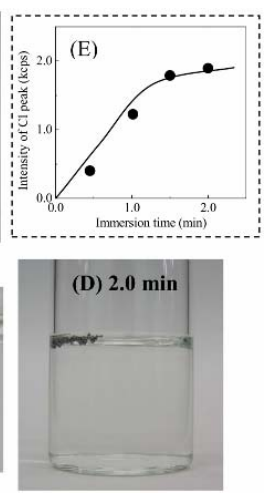

Figure 6. Photographs of $\mathrm{NaCl}$ particles covered with $\mathbf{P t}$ films in a bottle containing pure water after immersion times of (A) $0.5 \mathrm{~min}$, (B) $1.0 \mathrm{~min}$, (C) $1.5 \mathrm{~min}$, and (D) 2.0 min. (E) Intensity of Cl peak obtained by XRF measurements of the solution used for the immersion test as a function of immersion time.

floating particles retained their cubic shape, as seen in the magnified photograph of Figure 6(C).

To investigate the reasons for the particles floating, the solution composition at each immersion time was analyzed by XRF, with the result that $\mathrm{Cl}$ was detected. Figure 6(E) shows the intensity of the observed $\mathrm{Cl}$ peak plotted against immersion time. The data were obtained at the ratio of sample weight/water volume of $1.5 \mathrm{mg} / \mathrm{ml}$. The peak intensity increased linearly until an immersion time of $1 \mathrm{~min}$, and then increased more gradually. This indicates that the $\mathrm{NaCl}$ particles inside the Pt films dissolved during immersion in water. However, as described in Figure 6(C), the floating samples retained their original cubic shape, implying that the dissolution 


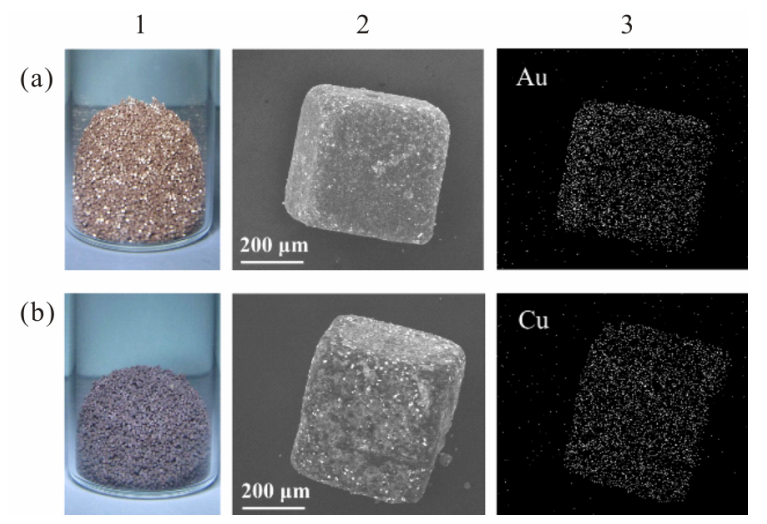

Figure 7. (1) Photographs, (2) FE-SEM images, and (3) EDS mapping images of (a) Au and (b) Cu-sputtered $\mathrm{NaCl}$ particles (magnification of FE-SEM and EDS images: $\times 110$ ).

of $\mathrm{NaCl}$ was not attributed to the collapse of the Pt films, but to the permeation of water through the Pt films. Remember that there were no remarkable pores or damage in the $\mathrm{Pt}$ films formed on the $\mathrm{NaCl}$ particles, as depicted in Figure 4. Therefore, it is assumed that the deposited Pt films contained invisible defects such as grain boundaries through which water molecules could permeate, resulting in gradual dissolution of the $\mathrm{NaCl}$ particles. Furthermore, the tendency of the particles to float suggests that the permeation of water through the Pt films was very slow, leading to the formation of hollow particle-like materials. This unique characteristic may be useful in biomedical applications such as drug-delivery systems [33,34].

Sputtering with $\mathrm{Au}$ and $\mathrm{Cu}$ was also performed to investigate the effect of the kind of sputtered metal on surface modification of the $\mathrm{NaCl}$ particles. Photographs of the samples after sputtering with $\mathrm{Au}$ and $\mathrm{Cu}$ are illustrated in Figures 7(1a) and (1b), respectively. For both samples, their color changed to that originating from the sputtered metals. When the particles in each sample were observed by FE-SEM and EDS, Au or $\mathrm{Cu}$ was detected correspondingly and the EDS mapping images reflected the SEM images (see Figures 7(2) and (3)). From Figure 7 , it is clear that coating the $\mathrm{NaCl}$ particles with a uniform film is achieved by our sputtering method independent of the kind of sputtered metal.

\section{Conclusion}

In this study, $\mathrm{NaCl}$ particles coated with metal films were prepared using the polygonal barrel-sputtering method. Metal films composed of $\mathrm{Pt}, \mathrm{Au}$, or $\mathrm{Cu}$ were uniformly deposited on all of the $\mathrm{NaCl}$ particles, demonstrating that the polygonal barrel-sputtering method can be used for surface modification of water-soluble and water-reactive particles. In addition, based on the results of this study and our previous reports, our sputtering method makes it possible to uniformly modify the surfaces of various powder samples with not only metals but also alloys, metal oxides, and so on. Consequently, the polygonal barrelsputtering method is useful in the research and development of functionalized powder materials.

\section{REFERENCES}

[1] P. Tolmacsov, A. Gazsi and F. Solymosi, "Decomposition and Reforming of Methanol on Pt Metals Supported by Carbon Norit," Applied Catalysis A: General, Vol. 362, No. 1-2, 2009, pp. 58-61. doi:10.1016/j.apcata.2009.04.015

[2] B. Grbic, N. Radic, Z. Arsenijevic, R. Garic-Grulovic and Z. Grbavcic, "Structure Sensitivity of Dimethylamine Deep Oxidation over $\mathrm{Pt} / \mathrm{Al}_{2} \mathrm{O}_{3}$ Catalysts," Applied Catalysis B: Environmental, Vol. 90, No. 3-4, 2009, pp. 478-484. doi:10.1016/j.apcatb.2009.04.008

[3] M. Ruta, N. Semagina and L. Kiwi-Minsker, "Monodispersed Pd Nanoparticles for Acetylene Selective Hydrogenation: Particle Size and Support Effects," The Journal of Physical Chemistry C, Vol. 112, No. 35, 2008, pp. 13635-13641. doi:10.1021/jp803800w

[4] J. S. Jang, S. H. Choi, H. G. Kim and J. S. Lee, "Location and State of $\mathrm{Pt}$ in Platinized $\mathrm{CdS} / \mathrm{TiO}_{2}$ Photocatalysts for Hydrogen Production from Water under Visible Light," The Journal of Physical Chemistry C, Vol. 112, No. 44, 2008, pp. 17200-17205. doi:10.1021/jp804699c

[5] L. M. Torres-Martínez, R. Gómez, O. Vázquez-Cuchillo, I. Juárez-Ramírez, A. Cruz-López and F. J. AlejandreSandoval, "Enhanced Photocatalytic Water Splitting Hydrogen Production on $\mathrm{RuO}_{2} / \mathrm{La}: \mathrm{NaTaO}_{3}$ Prepared by Sol-Gel Method," Catalysis Communications, Vol. 12, No. 4, 2010, pp. 268-272. doi:10.1016/j.catcom.2010.09.032

[6] L. J. Fu, H. Liu, C. Li, Y. P. Wu, E. Rahm, R. Holze and H. Q. Wu, "Surface Modifications of Electrode Materials for Lithium Ion Batteries," Solid State Sciences, Vol. 8, No. 2, 2006, pp. 113-128.

doi:10.1016/j.solidstatesciences.2005.10.019

[7] Z. B. Wang, G. P. Yin and P. F. Shi, "New Pt-Ru Solid Compounds as Precursors of Anodic Catalysts for Direct Methanol Fuel Cell," Journal of Alloys and Compounds, Vol. 420, No. 1-2, 2006, pp. 126-132. doi:10.1016/j.jallcom.2005.10.042

[8] Y. Chen, Y. Zhou, Y. Tang and T. Lu, "Electrocatalytic Properties of Carbon-Supported Pt-Ru Catalysts with the High Alloying Degree for Formic Acid Electrooxidation," Journal of Power Sources, Vol. 195, No. 13, 2010, pp. 4129-4134. doi:10.1016/i.jpowsour.2010.01.054

[9] B. N. Popov, X. Li, G. Liu and J.-W. Lee, "Power Source Research at USC: Development of Advanced Eelectrocatalysts for Polymer Electrolyte Membrane Fuel Cells," International Journal of Hydrogen Energy, Vol. 36, No. 2, 2011, pp. 1794-1802. doi:10.1016/j.ijhydene.2009.12.050

[10] V. M. Aroutiounian, A. Z. Adamyan, E. A. Khachaturyan, Z. N. Adamyan, K. Hernadi, Z. Pallai, Z. Nemeth, L. Forro, A. Magrez and E. Horvath, "Study of the Surface- 
Ruthenated $\mathrm{SnO}_{2}$ /MWCNTs Nanocomposite Thick-Film Gas Sensors," Sensors and Actuators B, Vol. 177, 2013, pp. 308-315. doi:10.1016/j.snb.2012.10.106

[11] H.-K. Lee, H.-Y. Lee and J.-M. Jeon, "Codeposition of Micro- and Nano-Sized SiC Particles in the Nickel Matrix Composite Coatings Obtained by Electroplating," Surface \& Coatings Technology, Vol. 201, No. 8, 2007, pp. 47114717. doi:10.1016/j.surfcoat.2006.10.004

[12] Y.-G. Zhou, N. V. Rees and R. G. Compton, "Nanoparticle-Electrode Collision Processes: The Electroplating of Bulk Cadmium on Impacting Silver Nanoparticles," Chemical Physics Letters, Vol. 511, No. 4-6, 2011, pp. 183186. doi:10.1016/j.cplett.2011.06.015

[13] Y. Xiang, L. Yang, W. Cheng-biao, L. Xin-chun and Y. De-yang, "Investigation on Preparation and Properties of Thick DLC Film in Medium-Frequency Dual-Magnetron Sputtering," Vacuum, Vol. 80, No. 4, 2005, pp. 324-331. doi:10.1016/j.vacuum.2005.06.002

[14] M. Alvisi, G. Galtieri, L. Giorgi, R. Giorgi, E. Serra and M. A. Signore, "Sputter Deposition of Pt Nanoclusters and Thin Films on PEM Fuel Cell Electrodes," Surface \& Coatings Technology, Vol. 200, No. 5-6, 2005, pp. 13251329. doi:10.1016/j.surfcoat.2005.07.093

[15] C. Lee and J. Bae, "Oxidation-Resistant Thin Film Coating on Ferritic Stainless Steel by Sputtering for Solid Oxide Fuel Cells," Thin Solid Films, Vol. 516, No. 18, 2008, pp. 6432-6437. doi:10.1016/j.tsf.2008.02.045

[16] T. Wang, X. Diao and X. Wang, "Inhomogeneous Optoelectronic and Microstructure Property Distribution across the Substrate of ZnO:Al Films Deposited by Room Temperature Magnetron Sputtering," Applied Surface Science, Vol. 257, No. 23, 2011, pp. 9773-9779. doi:10.1016/j.apsusc. 2011.06 .010

[17] T. Abe, S. Higashide, M. Inoue and S. Akamaru, "Surface Modification of Fine Particles with a $\mathrm{SnO}_{2}$ Film by Using a Polyhedral-Barrel Sputtering System," Plasma Chemistry and Plasma Processing, Vol. 27, No. 6, 2007, pp. 799-811. doi:10.1007/s11090-007-9100-4

[18] M. Hara, Y. Hatano, T. Abe, K. Watanabe, T. Naitoh, S. Ikeno and Y. Honda, "Hydrogen Absorption by Pd-Coated ZrNi Prepared by Using Barrel-Sputtering System," Journal of Nuclear Materials, Vol. 320, No. 3, 2003, pp. 265-271. doi:10.1016/S0022-3115(03)00189-2

[19] T. Abe, S. Akamaru and K. Watanabe, "Surface Modification of $\mathrm{Al}_{2} \mathrm{O}_{3}$ Ceramic Grains Using a New RF Sputtering System Developed for Powdery materials," Journal of Alloys and Compounds, Vol. 377, No. 1-2, 2004, pp. 194-201. doi:10.1016/j.jallcom.2003.12.053

[20] S. Akamaru, S. Higashide, M. Hara and T. Abe, "Surface Coating of $\mathrm{Small}_{\mathrm{SiO}}$ Particles with $\mathrm{TiO}_{2}$ Thin Layer by Using Barrel-Sputtering System," Thin Solid Films, Vol. 513, No. 1-2, 2006, pp. 103-109. doi:10.1016/j.tsf.2006.01.056

[21] T. Abe, H. Hamatani, S. Higashide, M. Hara and S. Akamaru, "Surface Coating of $\mathrm{Small}_{\mathrm{SiO}_{2}}$ Particles with a $\mathrm{WO}_{3}$ Thin Film by Barrel-Sputtering Method," Journal of Alloys and Compounds, Vol. 441, No. 1-2, 2007, pp. 157-161. doi:10.1016/i.jallcom.2006.07.132

[22] A. Taguchi, M. Inoue, C. Hiromi, M. Tanizawa, T. Kita- mi and T. Abe, "Study of the Surface Morphology of Platinum Thin Films on Powdery Substrates Prepared by the Barrel Sputtering System," Vacuum, Vol. 83, No. 3, 2009, pp. 575-578. doi:10.1016/j.vacuum.2008.04.023

[23] T. Abe, M. Tanizawa, K. Watanabe and A. Taguchi, " $\mathrm{CO}_{2}$ Methanation Property of $\mathrm{Ru}$ Nanoparticle-loaded $\mathrm{TiO}_{2}$ Prepared by a Polygonal Barrel-Sputtering Method," Energy \& Environmental Science, Vol. 2, No. 3, 2009, pp. 315-321. doi:10.1039/b817740f

[24] S. Akamaru, M. Inoue, Y. Honda, A. Taguchi and T. Abe, "Preparation of Ni Nanoparticles on Submicron-Sized $\mathrm{Al}_{2} \mathrm{O}_{3}$ Powdery Substrate by Polyhedral-Barrel-Sputtering Technique and Their Magnetic Properties," Japanese Journal of Applied Physics, Vol. 51, No. 6, 2012, Article ID: 065201. doi:10.1143/JJAP.51.065201

[25] T. Abe, S. Akamaru, K. Watanabe and Y. Honda, "Surface Modification of Polymer Microparticles Using a Hexagonal-Barrel Sputtering System," Journal of Alloys and Compounds, Vol. 402, No. 1-2, 2005, pp. 227-232. doi:10.1016/j.jallcom.2005.02.097

[26] A. Taguchi, T. Kitami, H. Yamamoto, S. Akamaru, M. Hara and T. Abe, "Surface Coating with Various Metals on Spherical Polymer Particles by Using Barrel Sputtering Technique," Journal of Alloys and Compounds, Vol. 441, No. 1-2, 2007, pp. 162-167. doi:10.1016/i.jallcom.2006.07.131

[27] S. Akamaru, H. Yamamoto and T. Abe, "Surface Coating of Microparticles with Tungsten Carbide by Using the Barrel Sputtering System," Vacuum, Vol. 83, No. 3, 2009, pp. 633-636. doi:10.1016/j.vacuum.2008.04.052

[28] H. Yamamoto, K. Hirakawa and T. Abe, "Surface Modification of Carbon Nanofibers with Platinum Nanoparticles Using a 'Polygonal Barrel-Sputtering' System," Materials Letters, Vol. 62, No. 14, 2008, pp. 2118-2121. doi:10.1016/j.matlet.2007.11.039

[29] M. Inoue, H. Shingen, T. Kitami, S. Akamaru, A. Taguchi, Y. Kawamoto, A. Tada, K. Ohtawa, K. Ohba, M. Matsuyama, K. Watanabe, I. Tsubone and T. Abe, "Preparation and Physical and Electrochemical Properties of Carbon-Supported Pt-Ru (Pt-Ru/C) Samples Using the Polygonal Barrel-Sputtering Method," The Journal of Physical Chemistry C, Vol. 112, No. 5, 2008, pp. 14791492. doi:10.1021/jp075400o

[30] M. Inoue, T. Nishimura, S. Akamaru, A. Taguchi, M. Umeda and T. Abe, "CO Oxidation on Non-Alloyed Pt and $\mathrm{Ru}$ Electrocatalysts Prepared by the Polygonal BarrelSputtering Method," Electrochimica Acta, Vol. 54, No. 21, 2009, pp. 4764-4771. doi:10.1016/j.electacta.2009.04.009

[31] M. Inoue, S. Akamaru, A. Taguchi and T. Abe, "Physical and Electrochemical Properties of Pt-Ru/C Samples Prepared on Various Carbon Supports by Using the Barrel Sputtering System," Vacuum, Vol. 83, No. 3, 2009, pp. 658-663. doi:10.1016/j.vacuum.2008.04.042

[32] C. Hiromi, M. Inoue, A. Taguchi and T. Abe, "Optimum $\mathrm{Pt}$ and $\mathrm{Ru}$ Atomic Composition of Carbon-Supported Pt$\mathrm{Ru}$ Alloy Electrocatalyst for Methanol Oxidation Studied by the Polygonal Barrel-Sputtering Method," Electrochimica Acta, Vol. 56, No. 24, 2011, pp. 8438-8445. 
doi:10.1016/j.electacta.2011.07.023

[33] I. Fenoglio, B. Fubini, E. M. Ghibaudi and F. Turci, "Multiple Aspects of the Interaction of Biomacromolecules with Inorganic Surfaces," Advanced Drug Delivery Reviews, Vol. 63, No. 13, 2011, pp. 1186-1209. doi:10.1016/j.addr.2011.08.001
[34] A.-M. Chacko, E. D. Hood, B. J. Zern and V. R. Muzykantov, "Targeted Nanocarriers for Imaging and Therapy of Vascular Iflammation," Current Opinion in Colloid \& Interface Science, Vol. 16, No. 3, 2011, pp. 215-227. doi:10.1016/j.cocis.2011.01.008 